local increase of temperature within certain subterranean horizons. But, as he himself admits, this way of putting the case brings us no nearer to what may be the ultimate cause of such a local increase of temperature. He seeks to prove that all the phenomena of volcanic action point to local excitation, and that the observed order of appearance of lavas is what on this view might theoretically be anticipated. It would be beyond the necessary limits of this article to follow him into the details of his argument. But one or two points may be briefly referred to. $\mathrm{He}$ regards lavas as mainly derived not from primeval subterranean magmas, but rather from the fusion of such rocks as the crystalline schists and sedimentary formations. In the mechanics of eruptions he believes that the outpouring of lava does not arise from the expansion of vapours absorbed within the molten magma, but is merely a hydrostatic problem of the simplest order-the lava being forced out by the weight of the rocks overlying its subterranean reservoirs.

According to this hypothesis two preliminary conditions are requisite for an eruption of lava-the rocks must be fused, and their density in the molten state must be less than that of the overlying rocks. The author regards the observed order of appearance of the lavas to be determined by their relative density and fusibility, the more siliceous requiring a higher temperature to fuse them, and the more basic, though less refractory, demanding a higher temperature to give them such a diminution of density as will permit them to be erupted. At an early stage of eruption he holds that the acid rocks may be light enough to be ejected, but are not yet melted, while the basic rocks may be melted but must await further expansion by access of heat before they are capable of being poured forth. Hence some intermediate rock will be selected as the first to issue, and this rock the author believes to be propylite. A further increase of temperature produces hornblendic andesite and trachyte, and so on to the rhyolites, and finally the basalts. All rocks more basic than propylite are stated to present evidence of superfusion, these rocks, according to the theory, being those which possess so high a density as to demand a much greater accession of heat than that required for mere fusion, in order that they may become lighter than the overlying crust, and thus be erupted. Basalt in particular is cited as an example of a superfused rock

The author tacitly assumes that the density of a lava at the time of its outflow is necessarily less than that of the rocks through which it ascends, otherwise it could not be erupted. It is a pity that no experimental demonstration of this assertion was given, for it forms so fundamental a postulate in the hypothesis. But even on the supposition that the lava is forced out by the descent of heavier overlying rock, what ought to be found as proof of this action? Ought we not to meet with abundant evidence of subsidence at volcanic foci? Every mass of lava derived from the local fusion of rocks at no great depth beneath the surface and driven out by the weight of rock overlying it, should have an accompanying and proportionate subsidence of the crust over the site of its source. Occasional proofs of collapse at volcanoes have long been known indeed, but admit of other explanation, such as "evisceration," to use Mr. Mallet's phrase. Instead of subsidence, the emission of volcanic material has generally been accompanied with upheaval. Capt. Dutton's own magnificent Plateaux of Utah should furnish copious proofs of a sinking or sagging of the nearly horizontal strata round the eruptive vents. But there is no trace of any structure of this kind in his instructive and carefully-drawn sections.

Again, the alleged superfusion of the basic rocks can hardly be admitted upon the evidence here brought forward in its support. The fact that thin streams of basalt have had a greater liquidity and have retained it for much greater distances than the acid lavas, has long been recognised. But as Reyer has recently suggested, it is capable of a different interpretation from that of superfusion. The author appeals also to the microscopic structure of basalt as favouring his view of former intense ignition. He cites, for example, the presence of glass particles, the absence of water-cavities, the isotropic base, the compactness and vitreous structure of this rock. But are not these characters present in far more striking development among the vitreous acid rocks, which he supposes to have had a temperature little more than sufficient for fusion? The exceptions which the author candidly admits to occur in the normal succession of lavas-basalts, for example, appearing before rhyolites, or quartz propylite and quartz-andesite simultaneously with the hornblendic members of their respective groups-seem fatal to the hypothesis.

From another point of view the idea that the order of emission of lavas has been determined in the way supposed presents great difficulties. The author affirms that "we must at least admit that the source of lavas is among segregated masses of heterogenous materials," and he supposes that "this arrangement would be well satisfied by a succession of metamorphic strata [gneiss, hornblendic and augitic schist] resting upon a supposed primitive crust or magma having a constitution approximating that of the basaltic group of rocks." But every known mass of metamorphic strata presents endless interstratifications of very various materials. By what process of selection are the elements of these diverse rocks grouped successively into definite volcanic compounds? How is it that out of the simmering subterranean broth just so much silica and alumina as are needed for one type are ladled out at one time, while a careful hand is kept on the lime, alkalies and iron-oxides, only the right proportions being dealt forth for each lava?

The remarkable persistence of type among the different species of lava all over the world has long been recognised. It is not easy to see how this persistence should exist, nor why there should not be far more varieties of lava and transitional grades between the varieties if they are due to the local melting up of various masses of heterogeneous materials within the crust.

The volume is illustrated by a series of heliotype plates, from photographs taken in the course of the survey, representing some of the more remarkable external forms assumed by the sedimentary and volcanic rocks. The Atlas contains a valuable series of topographical and geological maps. Among these a relief-map of the Plateaux, on the scale of five miles to an inch, is specially instructive. There are likewise two plates of sections, which bring before the eye in a clear and concise form the structural details of the region. In point of execution the plates of the atlas are altogether admirable. In his preface Capt. Dutton states that he undertook the task of exploration assigned to him with considerable diffidence in his ability to accomplish it. He must be congratulated on having achieved a signal succers. His work bears everywhere marks of the most conscientious and painstaking industry, great acuteness of observation, and not a little literary skill in the marshalling and presentation of the facts observed. Let us hope that the arrangement by which he was enabled to exchange the routine duties of an army officer for geolological field-work may be prolonged, and that in further prosecution of his explorations in the West he may live to issue other volumes as interesting and valuable as that which is noticed here.

ARCH. GEIKIE

\section{TWO NEW PLANETARY NEBULAE}

A PLANETARY nebula in R.A. I $8 \mathrm{~h} .25^{\circ} \mathrm{m}$. and A Dec. - $25^{\circ} 13^{\prime}$ was discovered at the Harvard College Observatory on the evening of July 13. A second 
nebula was found on the following evening in R.A. I $8 \mathrm{~h} .4^{\circ} 3 \mathrm{~m}$. and Dec. $-28^{\circ} 12^{\prime}$. Both, but particularly the first, are only minute, and can be with difficulty distinguished from stars, except by their spectra. The discovery was not the result of accident but of a search with a direct vision prism inserted between the objective and eyepiece of the 15 -inch telescope. A star appears as a coloured line of light, while a planetary nebula forms a bright point, and is recognised instantly in sweeping. Many hundred or thousand stars can thus be examined very rapidly, and a single nebula picked out from among them. This method promises to add very greatly to the list of known planetary nebulæ, which now number about fifty. Probably a systematic search for these objects crossing a considerable part of the heavens will be made at this Observatory. Our knowledge of that distribution will thus be greatly increased, and we shall know that their absence in certain parts of the sky is not due to an omission to look for them. Any planetary nebula as bright as a twelfth-magnitude star would probably be detected by the method proposed. Bright lines or other peculiarities in the stellar spectra will also be looked for.

Doubt has been thrown on many of the attempts to measure the parallax of planetary nebulæ owing to the haziness of the borders of these bodies. The minuteness of the disks of the nebulæ noted above could permit their positions to be determined with great precision, and would thus show a very minute parallax.

Cambridge, U.S., July I5 EDWARD C. PICKERING

\section{NOTES}

AN influential committee has been formed from among the members in the Section of Zoology of the Paris Academy of Sciences and others eminent in that department, to obtain subscriptions for a medal in honour of M. Milne.Edwards, the doyen of French zoologists.

A movement has been set on foot to obtain subscriptions to a memorial fund in honour of the late Rev. J. Clifton Ward, whose name must be well known to our readers as a working geologist who made valuable contributions to his science. Mr. Ward, moreover, did great service in promoting a love of science in Cumberland, and the Association for the Advancement of Literature and Science, for which he did so much, has taken the fund heartily up. It ought to receive many subscriptions outside of the Association, and we commend it to the liberality of our readers. Subscriptions should be sent to the Rev. Canon Battersby, St. John's Parsonage, Keswick, and to Mr. Edwin Jackson, hon. treasturer, Keswick I.ibrary and Scientific Society. It is proposed to expend the fund in the erection of a mural tablet in the church of St. John, Keswick, and the remainder in laying the foundation of a fund for the education of $\mathrm{Mr}$. Ward's two daughters.

In answer to a question in the House of Commons as to the cause of the delay in the removal of the Natural History Collection from the British Museum to South Kensington, and when that removal would be completed, Mr. Walpole said he believed the delay had been caused by the facts that the building in which the collection was to be placed was not handed over to the Trustees of the British Museum until June, and that the grant made by the Treasury was not sufficiently large to cover the whole estimated expense for the cost of the removal. He believed the removal of the mineralogical, geological, and botanical collection would be completed by the end of the year or in the spring of next year; and that as far as the zoological collection was concerned, its removal would depend very materially upon the grant which the Treasury might feel itself at liberty to make for the purpose.

PROF. Ed. VAN BENEDEN is at present at Bergen for the purpose of working out the embryonic development of the Lemming, which is likely to prove extremely interesting, because that of the guinea-pig is so abnormal.

A FEW months after Leverrier's death a commission was established for determining the best means of protecting collieries from fire-damp. The Commission has written a very long report recording the causes of 420 accidents. Sixty-four projects presented by private individuals have been examined, and some new instruments have been designed and are being constructed, viz., an anemometer by Vicaire, a manometer by Le Chatellier, and a registering apparatus for the quantity of air introduced into the galleries. But the composition of coal explosive dust has not been determined, nor the extent of its influence on catastrophes; the chemical analysis of Grisau has not been completed, and the salvage question has not been exhausted. The only substantial benefit is a compilation of mining regulations and a series of propositions which have been transmitted to the French Ministry, and will be laid before Parliament next session.

THE detailed programme of the annual meeting of the Iron and Steel Institute, to be held at Diisseldorf on August 25, 26, 27 , and 28 , is now published. The proceedings commence with a concert at the Tonhalle on Tuesday evening, August 24. On Wednesday there is to be in the morning a general meeting of members at the Tonhalle, where the institute will be received by the local authorities; in the afternoon a visit to the exhibition and to works near Diisseldorf; and in the evening the annual dinner of the institute at the Tonhalle. On Thursday and Friday there are to be general meetings in the morning for the reading and discussion of papers; the afternoons are to be devoted to excursions by special trains to various iron and steel works in the neighbourhood of Düsseldorf, followed by concerts in the evenings. The whole will be brought to a close by a Rhine excursion on Saturday, which is timed to bring members by $10.30 \mathrm{p} . \mathrm{m}$. to Cologne, viû Rolandseck, Bingen, and Coblentz. The general secretary is Mr. J. S. Jeans, whose address up till August 19 is 7, Westminster Chambers, Victoria Street; and after that date, Tonballe, Diisseldorf.

THE Aldini gold medal (worth 1,000 lire) will be awarded by the Academy of Sciences of the Institute of Bologna to the best memoir on galvanism (animal electricity). Memoirs to be written in Italian, Latin, or French, and sent in before June 30, $\mathbf{8} 882$.

THE Benele prizes (first, $\mathrm{r}, 700$ marlss; second, 60 marks) of the Philosophical Faculty of Göttingen University are offered for investigation, theoretical and experimental, of diffraction phenomena in the case of non-homocentric light sources, as, especially, a circular and a square luminous surface of uniform brightness of the emitted simple or compound white light. Memoirs to be written in German, Latin, Frencb, or English, and sent in before March I 1,1883 .

A NuW process for obtaining stereotypes for printing has been discovered by M. Emile Jeannin, a sculptor of Paris, who proposes to employ for that purpose the material known as celluloid. The process of preparation takes only half an hour, when the types are once set up, and the plates thus produced are remarkably suitable for working on cylinder machines running at a high speed, being very light, flexible, and very durable. In this last respect indeed they surpass metal plates, affording, it is said, 50,000 impressions, whereas even an electrotyped copper plate backed with lead will only last for 30,000 .

THE astronomical observatory established on the Trocadéro, is not the only scientific establishment which has found a home in the palace of the last Universal Exhibition. A number of microscopes have been arranged in a special room for the benefit of public instruction. The instruments lent by $M$. Joubert have been placed on the top of one of the towers, where a lift 